\title{
$5-2011$
}

\section{Teaching Students Personal and Social Responsibility With Measurable Learning Outcomes}

\author{
Frank Ardaiolo \\ Winthrop University \\ Steve Neilson \\ Rollins College \\ Timothy K. Daugherty \\ University of Wisconsin-Stout
}

Follow this and additional works at: https://digitalcommons.winthrop.edu/fac_pub

Part of the Scholarship of Teaching and Learning Commons

\section{Digital Commons Citation}

Ardaiolo, Frank; Neilson, Steve; and Daugherty, Timothy K., "Teaching Students Personal and Social Responsibility With Measurable Learning Outcomes" (2011). Winthrop Faculty and Staff Publications. 71. https://digitalcommons.winthrop.edu/fac_pub/71

This Article is brought to you for free and open access by Digital Commons @ Winthrop University. It has been accepted for inclusion in Winthrop Faculty and Staff Publications by an authorized administrator of Digital Commons @ Winthrop University. For more information, please contact digitalcommons@mailbox.winthrop.edu. 


\title{
Journal of College \& Character
}

\section{Teaching Students Personal and Social Responsibility With Measurable Learning Outcomes}

\author{
Frank P. Ardaiolo, Winthrop University \\ Steve Neilson, Rollins College \\ Timothy K. Daugherty, University of Wisconsin-Stout ${ }^{1}$
}

\begin{abstract}
In 2005 the Association of American Colleges and Universities launched a national initiative that championed the importance of a 21 st-century liberal education. What was unique about this initiative was the underlying assumption that educating for personal and social responsibility was "core" for an educated citizenry and should be taught. So the question became "How does higher education teach responsibility?" Student affairs divisions at Winthrop University and Rollins College approached this question by focusing on collaborative programs and student learning experiences in the curriculum and cocurriculum with the ability to measure outcomes.
\end{abstract}

T 2005 the Association of American Colleges and Universities (AAC\&U) launched a national 1 initiative that championed the importance of a 21 st-century liberal education. Essential student learning outcomes were established around four domains. These were knowledge of human cultures and the physical and natural world, intellectual and practical skills, personal and social responsibility (PSR), and integrated and applied learning.

The project established to address the third learning domain, having to do with PSR, was called Core Commitments. The inclusion of this separate program within AAC\&U that presumes to teach PSR is quite a remarkable statement about the critical role higher education plays in teaching students to understand and explore their ethical responsibilities to themselves and others. This was a remarkable call for returning to the root roles of the early American colleges, where character development was considered even more important than the solitary growth of the intellect (Rudolf, 1962).

The AAC\&U (2010a) Core Commitments' guiding philosophy challenges higher education institutions to "unapologetically teach personal and social responsibility" and calls for those in both the curriculum and cocurriculum to accept responsibility for student learning. They argue that "ethical, civic, and moral development should be closely tied to a substantive vision for student learning that is shared across constituent groups" (AAC\&U, 2010a).

To begin their initiative, AAC\&U identified a leadership consortium of 23 colleges and universities to develop campus programs on PSR. Rollins College (a small, private liberal arts

\footnotetext{
${ }^{1}$ Frank Ardaiolo is vice president for student life and an associate professor at Winthrop University. He cochairs the NASPA - Student Affairs Administrators in Higher Education task group on Core Commitments: Educating for Personal and Social Responsibility. Steve Neilson is special assistant to the president and was dean of student affairs and professor of theatre at Rollins College. He cochairs NASPA's task group on Core Commitments: Educating for Personal and Social Responsibility. Tim Daugherty is a professor of psychology and chair of the Psychology Department at the University of Wisconsin-Stout. His work with college curricula and assessment has addressed both general education and the major.
} 
institution) and Winthrop University (a medium-sized, public comprehensive university) are two members of the Core Commitments Leadership Consortium. Our institutions have been working for the last 3 years, building curricular and cocurricular frameworks for students to learn key tenants of PSR. PSR is the forefront of a movement that we hope will build integrated learning experiences for students, blurring distinctions between learning in the curriculum and learning in the cocurriculum. Hundreds of educators from each member institution met together several times to explore the meaning and application of sound pedagogy to deepen students' PSR:

Core Commitments aims to reclaim and revitalize the academy's role in fostering students' development of personal and social responsibility. The initiative focuses national attention on the importance of students exploring their ethical responsibilities to self and others. It is designed to help campuses create learning environments in which all students reach for excellence in the use of their talents, take responsibility for the integrity and quality of their work, and engage in meaningful practices that prepare them to fulfill their obligations in an academic community and as responsible global and local citizens. (AAC\&U, 2010a)

The majority of the participants in the Leadership Consortium institutions were academic administrators or faculty members. We were struck with how few student affairs educators were part of institutional teams and shocked to learn how few of the teams selected actually knew what student affairs really did on their respective campuses. On the other hand, as we explored the literature on educating students for PSR with broad topics like fostering civic engagement, promoting common deep learning, and renewing the commitment of the liberal arts, we kept saying to ourselves and each other, "We do that!" We were once again reminded of the chasm between academic and student affairs on many campuses and the simple but long-standing failure to bridge our coexisting cultures.

Our epiphany arrived when we realized there was common language being used within the Learning Reconsidered (2004) monograph, stimulated by NASPA - Student Affairs Administrators in Higher Education and ACPA - College Student Educators International, and the AAC\&U project on Core Commitments for Educating Students for PSR. There is great congruence between PSR's Core Commitments of the following:

- Cultivating Personal and Academic Integrity

- Contributing to a Larger Community

- Taking Seriously the Perspective of Others

- Striving for Excellence

- Developing Competence in Moral and Ethical Reasoning (AAC\&U, 2010a)

... and the student outcomes outlined in Learning Reconsidered:

- Cognitive complexity

- Knowledge acquisition, integration, and application

- Humanitarianism

- Civic engagement

- Interpersonal and intrapersonal competence

- Practical competence

- Persistence and academic achievement (NASPA, 2004)

When we speak to faculty colleagues about teaching content, we will often diplomatically state, "It's not important what you teach; it's only important what your students learn." We found this to be particularly true when the focus is on students learning PSR. This is so because many students systematically fail to recognize the value of learning (Tagg, 2003). Tagg wrote that students, 
while commonly physically present on our campuses, are simultaneously psychologically absent. He maintained that the fundamental challenge facing colleges today is to change the expectations of incoming students concerning their attitudes and their beliefs about how they think about their school setting, academic work, and their own relationship to academic institutions:

What we can say with fair confidence at this point is that most students who leave high school and enter college bring with them a set of attitudes and beliefs about schooling and their interaction with educational institutions that tend to insulate them against learning rather than to prepare them for it. (Tagg, 2003, p. 47)

Herein lie the challenges that face our institutions - how to go about systematically addressing the attitudes, beliefs, and actions of students' personal and social responsibilities in a manner that is impactful, assessable, and sustainable to an institution-wide audience who may not be psychologically present or even predisposed to address such matters. At our universities, we decided that engagement across many university actors and student domains was the key to addressing the core commitments agenda. As Pascarella and Terenzini (2005) reflected on the totality of the college experience,

In some areas of intellectual development (including critical thinking), the breadth of student involvement in the intellectual and social experiences of college, rather than any particular type of involvement, matters most. The greatest impact appears to stem from students' total level of campus engagement, particularly when academic, interpersonal, and extracurricular involvements are mutually reinforcing and relevant to a particular educational outcome. (p. 647)

At Winthrop and Rollins we have worked to engage students seamlessly and fully in experiences in and out of the classroom. Student learning is deepened when learning occurs on multiple levels - cognitive, affective, interpersonal, and spiritual. We believe that significant learning occurs around the Core Commitments' framework because meaning making is more than cognition. Cognition (NASPA, 2004) involves the thought processes that people use to analyze and synthesize information in order to make meaning of a situation or to decide how to respond to it. Cognitive development builds the capacity for reflective judgment, which describes a person's increasing ability to take information and context into account when developing judgments or making decisions. More distinctly, meaning making comprises students' efforts to comprehend the essence and significance of events, relationships, and learning; to gain a richer understanding of themselves in a larger context; and to experience a sense of wholeness. Meaning making arises in a reflective connection between a person or individual and the wider world (NASPA, 2004, p. 17).

Winthrop University and Rollins College took two different approaches to incorporate PSR into their educational processes. Winthrop worked with teams of collaborating student affairs professionals and faculty to build both curricular and cocurricular experiences that educated for PSR. Rollins adopted two paths. The faculty addressed PSR in the curriculum while student affairs and academic affairs staff taught PSR through peer educators. Most important, there were resonance within student affairs and easy adoption of the core commitments because they echoed the language of the student learning outcomes in Learning Reconsidered (NASPA, 2004).

\section{The Winthrop University Process}

$\mathrm{T}$ he framework of core commitments provided Winthrop a powerful cognitive and instrumental construct for achieving what we set out to accomplish. We found the Core Commitments focus allowed for variables that when combined created much institutional power and momentum 
characterized by high-level buy-in, purposeful and instrumental planning, assessable results, accountability, and sustainable interactions, bridging the gap between students' in-class learning and out-of-class experiences (Winthrop University, 2009).

From the start, we intentionally avoided the typical grant routine that often implements a discrete set of efforts on the periphery. Too often, grant-funded initiatives become token projects that evaporate into ephemeral buzz terminology. Intentionality started with the formation of our proposal writing team; its diversity served to strengthen the proposal and to insure that the project would immediately benefit from well-informed emissaries to all corners of campus. The implementation team similarly featured diverse representation from both academic affairs and student affairs (and, in the second year, the student body). Through this purposefully composed team, we sought to find and exploit the genuine synergies between the Core Commitments program and every program on our campus. Our faculty and staff are dedicated - but they are also wary of role overload and mission creep, where more and more demands are placed upon them and their most important primary roles are forgotten. Were core commitments just "more commitments"? We knew this concern had to be considered as we planned. Thus, we did not set out to superimpose a foreign framework; rather, we carefully evaluated the places and processes through which seamless integration could occur.

Departments in student affairs were oriented to the Core Commitments and challenged to plan and communicate in terms of the five dimensions. The departments immediately found resonance between the dimensions and current practices, and they benefited immensely from the common language provided by core commitments - a language that could be used within and between departments as well as between academic affairs and student affairs.

Winthrop's second year with the Core Commitments project started in August 2008 with prominent placement of Core Commitments in Winthrop's Vision of Distinction-a dynamic institutional planning document that is updated with annual objectives determined through processes of assessment and community decision making (Winthrop University, 2010a). Also in August, we presented the first year's Personal Social and Responsibility Inventory (PSRI) results (designed by the AAC\&U project team) to the more than 100 participants at the university's annual academic leadership retreat and invited campus leaders into reflection and planning. Results were posted online, and the whole community was invited to a subsequent session hosted by the Teaching and Learning Center on our campus.

The five dimensions became the lingua franca of Winthrop's SEED (Student Engagement, Excellence, and Development) Conference, an event that demonstrated the depth of institutionalization for Core Commitments at Winthrop. Over 100 participants from a variety of backgroundsfaculty, staff, and student leaders - devoted the first day of spring vacation to more than 20 interdisciplinary breakout sessions focused on student excellence, engagement, and development in the context of our core commitments. Through that conference, we pivoted as a community from time-limited grant to enduring identity.

\section{Key Accomplishments at Winthrop}

$\mathrm{T}$ able 1 provides a brief summary of activities started during each of the funded 2 years of the Core Commitments grant at Winthrop. Many activities, of course, continue, so it is important not to read the table as a list of discrete events. Rather, the gestalt of the table suggests coherence and direction.

Indeed, the greatest accomplishment of the first 2 years may be the fact that we would have a hard time removing Core Commitments from campus life at this point. In many places, persons, and processes at Winthrop University, the dimensions of PSR have taken root and become organic.

How many students are being affected? No student at Winthrop can avoid Core Commitments. These wholly owned commitments are now integrated into the Touchstone Core (our 
Table 1. Brief Summary of Winthrop Activities During the Grant Period

\begin{tabular}{|c|c|}
\hline $2007-2008$ & 2008-2009 \\
\hline CC Theme for 2007 Academic Leadership Retreat & PSRI results presented at 2008 Academic Leadership Retreat \\
\hline CC cited in 2007 Vision of Distinction & CC featured in 2008 Vision of Distinction \\
\hline $\begin{array}{l}\text { CC collaboration initiated with Council of } \\
\text { Student Leaders }\end{array}$ & $\begin{array}{l}\text { CC collaboration with Council of Student Leaders to revise } \\
\text { Dedication for Excellence }\end{array}$ \\
\hline PSRI promoted and administered & PSRI results reviewed at Teaching \& Learning Center workshop \\
\hline $\begin{array}{l}\text { Faculty training for two core courses revised to } \\
\text { incorporate CC: ACAD } 101 \text { and HMXP } 102\end{array}$ & $\begin{array}{l}\text { CC explicitly added to ACAD } 101 \text { course goals (ACAD } 101 \text { is } \\
\text { completed by all first-time entering students) }\end{array}$ \\
\hline $\begin{array}{l}\text { CC presented to each department in the Division } \\
\text { of Student Affairs }\end{array}$ & $\mathrm{CC}$ incorporated into new faculty and staff orientation programs \\
\hline Advanced faculty $\mathrm{CC}$ workshop presented & $\begin{array}{l}\text { CC featured in campus style manual (required for writing } \\
\text { sequence) }\end{array}$ \\
\hline $\begin{array}{l}\text { Broad community engaged in CC through flyers } \\
\text { at televised basketball game }\end{array}$ & $\begin{array}{l}\text { Winthrop's SEED Conference framed interdivisional work with } \\
\text { CC; follow-up roundtable scheduled to insure that framing } \\
\text { endures }\end{array}$ \\
\hline $\mathrm{CC}$ website established for community & $\begin{array}{l}\text { CC Interactive Tutorial concept developed (required for all } \\
\text { incoming students in ACAD 101) }\end{array}$ \\
\hline $\begin{array}{l}\text { CC material introduced to pilot section of HMXP } \\
102\end{array}$ & CC material included in sixth edition of HMXP reader \\
\hline $\mathrm{RA}$ training revised to incorporate $\mathrm{CC}$ & LEAD 120 course for RAs developed with CC \\
\hline $\begin{array}{l}\text { Orientation assistant training revised to } \\
\text { incorporate } \mathrm{CC}\end{array}$ & Peer mentor training revised to incorporate $\mathrm{CC}$ \\
\hline PSRI data examined and reviewed & PSRI data posted for campus community access \\
\hline \multirow[t]{3}{*}{$\begin{array}{l}\text { Summer AAC\&U institute session delivered: } \\
\text { Models of Collective Engagement }\end{array}$} & $\begin{array}{l}\text { Session planned with consortia colleagues for the Network for } \\
\text { Academic Renewal Conference }\end{array}$ \\
\hline & $\begin{array}{l}\text { Campus Common Book Project framed around CC; book } \\
\text { customized to feature CC on back cover; CC banners placed on } \\
\text { campus; minigrants encouraged interdisciplinary teams to } \\
\text { develop related programming for community }\end{array}$ \\
\hline & $\begin{array}{l}\text { CC incorporated into residence hall programming and cultural } \\
\text { events }\end{array}$ \\
\hline
\end{tabular}

Note. ACAD $101=$ Principles of the Learning Academy; CC = Core Commitments; HMXP $102=$ Human Experience; LEAD $120=$ Theory and Practice of Residential Leadership; PSRI = Personal Social and Responsibility Inventory; RA = resident assistant; SEED = Student Engagement, Excellence, and Development.

general education program) courses and our student life programming. And we are serious about understanding impact. Through embedded assessment, we will know not just how many but how exactly students are being affected.

The developmental arc for PSR education is subject to change (growth and development, not elimination) as our community works through all possibilities, but the following arc is currently in place. Every new student at orientation during the past 3 years was handed a copy of the year's common book, which has been customized to introduce students to the five dimensions (Winthrop University, 2010b). When those same students arrived on campus in August, they subsequently completed an interactive online tutorial related to the five dimensions and enrolled in a freshman seminar course (ACAD 101) that emphasizes the role of PSR in their education. Students also have many events and programs available throughout the year related to the Common Book Project and Core Commitments. For at least 2 years, they will live in an Academic Success Community (residence hall) that promotes PSR. As they progress through the Touchstone Program (our general 
education program), they encounter Core Commitments in each of the Touchstone Core courses. Any student seeking a leadership or service role on campus will receive additional training related to PSR. Academic leaders and faculty are being encouraged and supported (e.g., through the SEED Conference) as they work to integrate PSR into major programs. Most significant for the future development of teaching and assessing PSR at Winthrop, the faculty conference in October 2010 adopted from its University-Wide Academic Assessment Committee four university-level competencies that all Winthrop undergraduates are expected to attain by graduation. Competency 2 states,

Winthrop graduates are personally and socially responsible.... [They] value integrity, perceive moral dimensions, and achieve excellence. They take seriously the perspectives of others, practice ethical reasoning, and reflect on experiences. Winthrop graduates have a sense of responsibility to the broader community and contribute to the greater good. (Costner et al., 2010, p. 17).

\section{Rollins College Focus on Peer Educators to Teach PSR}

$\mathrm{R}$ ollins College took a different slant toward incorporating the Core Commitments than that of Winthrop by approaching educating for PSR from two distinct perspectives. The faculty, as part of a curriculum review, voted to pilot the student learning objectives originally outlined in AAC\&U's (2010b) Liberal Education and America's Promise (LEAP initiative), which included the outcomes surrounding PSR. While Winthrop elected an integrated approach involving academic and student affairs educators, Rollins elected to develop an integrated approach focusing on student learning experiences outside the classroom.

Early in the process staff members in student affairs and academic affairs met and discussed the nature of their interaction with students and learning objectives as a consequence of that interaction with students. The group focused on AAC\&U's Core Commitments and the learning outcomes associated with the six dimensions of PSR: striving for excellence, cultivating personal and academic excellence, contributing to the larger community, taking seriously the perspective of others, and developing competence in ethical and moral reasoning.

To begin the process, the group designed a learning matrix for peer educators on these five dimensions (see Exhibit 1). The matrix was designed so that staff could provide an objective evaluation of how students demonstrated their understanding of PSR and applied it to their positions. Peer educators included resident assistants (RAs), student hearing boards, fraternity/sorority leaders, academic tutors, peer mentors, health educators, and others.

Because most peer educators participate in orientation or training, these seemed like natural places to launch a common curriculum. From there, each staff member and each department designed its own processes to teach this now common curriculum.

Rollins' residential life staff developed a performance appraisal matrix that was used by staff members to evaluate student RAs on the learning outcomes of PSR. One example asked the staff member to assess the RA's ability to develop competency in ethical and moral reasoning, and the metrics were (1) failed to become familiar with rules, policies, and procedures; (2) modeled rules, policies, and procedures; (3) adapted rationale addressing novel situations or gray areas; (4) created an inclusive climate enhancing the quality of life for others; (5) reflected a deep understanding of how value decisions and ethical decisions enhance communities, understanding, and the quality of life.

The Office of Community Standards (for student judicial matters) evaluated each member of the student hearing board using the five dimensions of PSR. Fraternity and sorority life introduced 


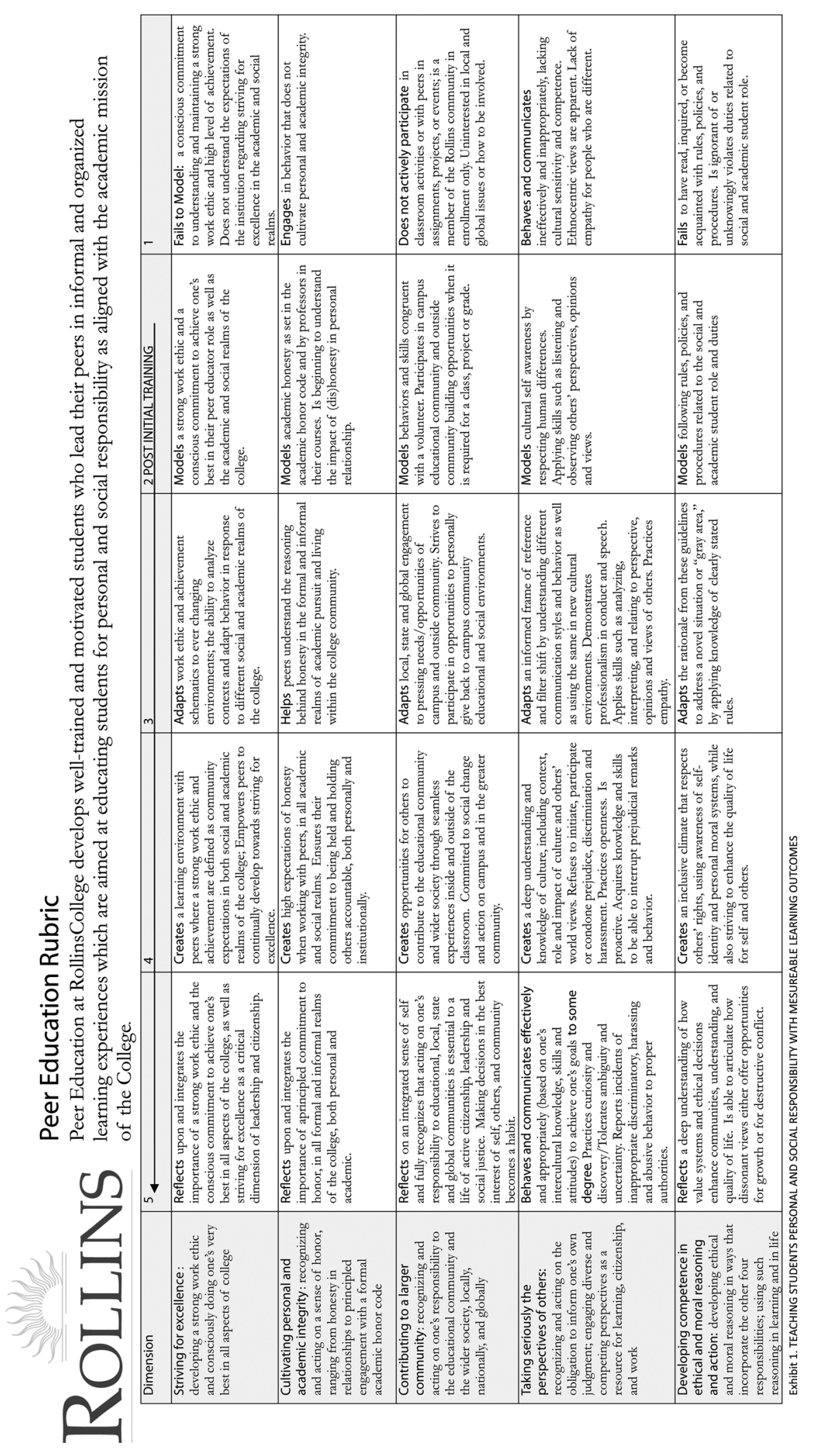


PSR in work with the Interfraternity Council and Panhellenic Council. Counseling and psychological services, while of course embracing issues of responsibility when dealing with clients, broadened their approach in key areas of alcohol screening and intervention and other health promotion programs.

The first-year program for new students, Explorations, now requires peer mentors to complete three programs within each of the five dimensions of PSR and then uses the student learning matrix to evaluate the peer mentors' performance. Other offices on campus - community engagement, student involvement and leadership, career services, multicultural affairs, health services, and academic tutors - are also addressing and measuring student learning around the articulated outcomes in Core Commitments: Educating for Personal and Social Responsibility (AAC\&U, 2010a).

\section{Promising Practices and the Big Picture}

$\mathrm{W}$ hile breathing life into written pledges of education for PSR, Rollins College and Winthrop University depended on community support. The chief academic officers and the chief student life officers were active, vested members of the campus' Core Commitments team. They attended every meeting and modeled a collegial openness that insured critical innovative processes were not stifled; at the same time, they used their positions effectively to insure institutional follow-through and support for team initiatives. The teams as a whole were both flexible and focused-flexible with means yet focused on the goal of deep, broad integration of the Core Commitments throughout campus. Plans emerged as broad templates, subject to community feedback that moved us forward with sure-footed steps.

While taking two different approaches incorporating PSR into their educational processes, Winthrop University and Rollins College worked with collaborating student affairs and faculty teams to build both curricular and cocurricular experiences.

For faculty and student affairs staff seeking new collaborations fueled by a common language across the administrative campus divide often found on many institutions, the five dimensions of AAC\&U's Core Commitments became the lingua franca of our institutions' educational innovations because they echoed the student learning outcomes student affairs knew from Learning Reconsidered (NASPA, 2004). An ongoing organic, fruitful, and significant arena developed on our campuses dedicated to teaching students PSR with measurable learning outcomes.

\section{References}

Association of American Colleges and Universities. (2010a). Core commitments: Educating students for personal and social responsibility. Retrieved from http://www.aacu.org /core_commitments/index.cfm

Association of American Colleges and Universities. (2010b). Liberal education and America's promise (LEAP). Retrieved from http://www.aacu.org/leap/index.cfm

Costner, C., Dannelly, S., DeRochi, J., Hayes, M., Johnson, J., Johnston, J., . . . Williams, M. (2010, September 10). University-Wide Academic Assessment Committee (UWAAC) report for Vice President of Academic Affairs Moore. Retrieved from http://www2.winthrop.edu/facultyconference/UWAAC_Final\%20Report_\%200910.pdf

NASPA - Student Affairs Administrators in Higher Education. (2004). Learning reconsidered: A campus-wide focus on the student experience. Washington, DC: Author.

Pascarella, E.T., \& Terenzini, P.T. (2005). How college affects students: Vol. 2. A third decade of research. San Francisco, CA: Jossey-Bass.

Rudolph, F. (1962). The American college and university: A history. New York, NY: Vintage Books. 
Tagg, J. (2003). The learning paradigm college. Bolton, MA: Anker.

Winthrop University. (2009). Core commitments: Connecting the Winthrop community, final report. Unpublished manuscript, Rock Hill, SC.

Winthrop University. (2010a). Vision of distinction, 2010-2011. Retrieved from http: //www.winthrop.edu/uploadedFiles/president/2010-11_VoD_color.pdf

Winthrop University. (2010b). Winthrop University Common Book Project. Retrieved from http://www2.winthrop.edu/universitycollege/Touchstone/CommonBook.htm 